\title{
Jahrestagung 2000
}

Vom 4. bis 7. Oktober hielt die Vereinigung der Deutschen Staatsrechtslehrer ihre Jahrestagung in Leipzig ab, wo sie bereits einmal im Jahre 1925 getagt hatte. Zu Beginn der Mitgliederversammlung gedachte die Vereinigung ihrer seit der Heidelberger Tagung verstorbenen Mitglieder Wilhelm G. Grewe und Karl Wenger. Der Vorsitzende konnte in der Mitgliederversammlung 25 Mitglieder begrüßen, die sich kurz vorstellten. Die Vereinigung zählt jetzt 491 Mitglieder.

$\mathrm{Zu}$ den Mitgliedern des Vorstandes für das Jahr 2001 wurden wiedergewählt: Jochen Abr. Frowein, Jörn Ipsen und Hartmut Bauer. Von der nächsten Tagung in Würzburg an wird der Vorstand gemäß der geänderten Satzungsbestimmung auf zwei Jahre gewählt.

Nach Begrüßung durch den Dekan der Juristenfakultät Professor Dr. Franz Häuser wurde bereits am Mittwoch nachmittag der erste Beratungsgegenstand der Tagung behandelt. Horst Dreier, Würzburg, und Walter Pauly, Jena, referierten über die deutsche Staatsrechtslehre in der Zeit des Nationalsozialismus. Die Aussprache stand unter der Leitung des Vorsitzenden. Im Anschluß daran gaben der Rektor der Universität Leipzig und der Oberbürgermeister der Stadt im Neuen Rathaus einen Empfang.

Am Donnerstag wurde der zweite Beratungsgegenstand behandelt. Über europäisches und nationales Verfassungsrecht sprachen Ingolf Pernice, Berlin, Peter M. Huber, Jena, Gertrude Lübbe-Wolff, Bielefeld, Christoph Grabenwarter, Bonn. Die Aussprache wurde von Hartmut Bauer geleitet. Am Abend dieses Tages gab der Ministerpräsident des Freistaates Sachsen, Professor Dr. Kurt Biedenkopf, im Festsaal des Alten Rathauses einen Empfang.

Der dritte Beratungsgegenstand wurde am Freitag behandelt. Wolfgang Löwer, Bonn, Thomas Puhl, Mannheim, Michael Holoubek, Wien, referierten über den Staat als Wirtschaftssubjekt und Auftraggeber. Die Aussprache wurde von Jörn Ipsen geleitet. Am Abend dieses Tages fand ein geselliger Abend im berühmten Auerbachs Keller statt, der durch musikalische Darbietungen bereichert wurde.

Der Ausflug am Samstag führte in die Gegend des Braunkohleabbaues südlich von Leipzig. Die Teilnehmer erhielten eingehende Informationen über die schwierigen Probleme des gegenwärtigen Tagebaues und der Rekultivierung abgebauter Braunkohlevorkommen. Das Be- 
gleitprogramm führte in vielen Alternativen in die Umgebung Leipzigs und hatte eine besondere Komponente in Musikangeboten.

Ganz besonderer Dank für die Vorbereitung der Tagung gilt Martin Oldiges und seinen Helfern sowie Frau Oldiges für die Organisation des Begleitprogramms. Leipzig hat sich auf dieser Tagung als eine Stadt des Rechts vorgestellt, die an ihre alten Traditionen auf diesem Gebiet intensiv anknüpft.

J.A.F. 